\title{
Environmental, Developmental and Genetic Factors Controlling Root System Architecture
}

F. Malekpoor Mansoorkhani ${ }^{a^{*}}$, G.B. Seymour ${ }^{\mathrm{a}}$, R. Swarup ${ }^{\mathrm{a}, \mathrm{b}}$, H. Moeiniyan Bagheri ${ }^{\mathrm{d}}$, R.J.L. Ramsey $^{\mathrm{e}}$ and A.J. Thompson ${ }^{\mathrm{c}}$

${ }^{a}$ Plant and Crop Sciences, School of Biosciences, University of Nottingham, Nottingham, United Kingdom; ${ }^{b}$ Centre for Plant Integrative Biology, University of Nottingham, Nottingham, United Kingdom; ${ }^{c}$ Environmental Science and Technology Department, School of Applied Sciences, Cranfield University, Cranfield, United Kingdom, ${ }^{d}$ Food Sciences Division, School of Biosciences, University of Nottingham, Nottingham, United Kingdom, ${ }^{e}$ Syngenta UK Ltd, Jealott's Hill International Research Centre, Bracknell United Kingdom

A better understanding of the development and architecture of roots is essential to develop strategies to increase crop yield and optimize agricultural land use. Roots control nutrient and water uptake, provide anchoring and mechanical support and can serve as important storage organs. Root growth and development is under tight genetic control and modulated by developmental cues including plant hormones and the environment. This review focuses on root architecture and its diversity and the role of environment, nutrient and water as well as plant hormones and their interactions in shaping root architecture.

\section{Introduction}

The green revolution brought dramatic increases in food production through the development of high yielding, dwarf varieties of rice and wheat and the application of large quantities of inorganic fertilizer, pesticides, and irrigation water. Unfortunately, this increased agricultural production has had a deleterious environmental impact increasing soil salinity, depleting and polluting water resources and using $\sim 8 \%$ world oil output. In addition, the world population is estimated to reach $\sim 8.3 \mathrm{Bn}$ by 2030 with the majority of that increase occurring in the developing world (Royal Society, 2009). The need to feed this growing population sustainably, and avoiding the significant threats to food crop harvests arising from climate change, could not be more pressing. With no more agricultural land available, increases in *Corresponding author. 
food production of between 40-50\% must be achieved through a sustainable intensification of agriculture over the next two decades (Royal Society, 2009).

The challenge of increasing crop production both with lower inputs of water and fertilizer as well as lower outputs in terms of greenhouse gas emissions is a significant one that will not be achieved without the translation of decades of basic research into plant biology. We know, for example, that root systems are central to the acquisition of water and nutrients by plants: Root system architecture (RSA) at both macro-scale (root length, branching and growth angle) and micro-scale (root diameter and root hair production) determines the distribution of root surface area within the soil profile and so the plant's capacity to capture nutrients and water (Lynch, 1995; Beaudoin et al., 2000; Hue et al., 2010; Osmont et al., 2007; Hochholdinger and Tuberosa, 2009, Coudert et al., 2010, Gewin, 2010; Atkinson et al., 2014). These traits therefore have a direct bearing on crop productivity, particularly under conditions of low resource availability (Lynch, 2007).

During recent years, the impact of the 'hidden half' on plant growth has become apparent in model systems such as Arabidopsis (Arabidopsis thaliana) and more importantly in crops like wheat (Triticum aestivum), rice (Oryza sativa), maize (Zea mays) and legumes (Goh et al., 2014; Bao et al., 2014; Herder et al., 2010; Coudert et al., 2010; Hochholdinger et al., 2004; De dorlodot et al., 2007). This review focuses on key factors influencing root system architecture.

\section{Roots - structure and diversity of form}

Roots have been defined as "axial multicellular structures of sporophytes of vascular plants which usually occur underground, have strictly apical elongation growth, and generally have gravitropic responses which range from positive gravitropism to diagravitropism, combined with negative phototropism" (Raven and Edwards, 2001; Sánchez-Calderón et al., 2013). Roots are essential for uptake of water and micro and macronutrients and also are the site of anchorage and constitute important storage organs. They additionally have a role in producing growth regulators that can be transported to the shoot and secondary metabolites such as flavonoids and alkaloids that can be involved in the defense against pathogens or in the cross talk with symbiotic microorganisms (Lynch and Brown, 2012; Montiel et al., 2004). Despite the importance of these organs there is still limited understanding of the mechanistic 
processes involved in many root functions. The root system results from the coordinated control of both genetic endogenous programs involving hormones and other developmental cues (regulating growth and organogenesis) and interactions with the soil and abiotic and biotic environmental stimuli (Hodge et al., 2009). The root system of most 'higher' plants can be classified into three types of roots, the primary, lateral and adventitious (Fitter, 1991). The main root axes elongate deeply into the soil providing the initial framework from which the whole root system can be developed. However the lateral roots, which can in some cases occupy more than $90 \%$ of the total length of the whole root system, eventually play the major role in water and nutrient uptake (Chaves et al., 2003; Horii et al., 2006).

Root systems can be classified according to branch structure, root activity or development. The classification based on development is the more useful to analyze the root system growth. This approach has been used to classify roots into three categories: primary root (PR), lateral roots (LR) and adventitious roots (shoot-borne root). This classification reflects the differences between monocotyledonous and dicotyledonous root system (Atkinson et al., 2014). Angiosperms have two main root system morphologies: allorhizic root system in dicots such as Arabidopsis, tomato and pea and homorhizic root system in monocots.

The allorhizic root system usually includes at least two root types: primary roots and lateral roots and are initially dominated by the primary root, which produces lateral roots. Even though adventitious roots are unusual in allorhizic systems, they can occur, particularly in response to wounding they can emerge from the hypocotyl or stems, in particularly in response to wounding (Atkinson et al., 2014, Osmont et al., 2007).

In contrast, the homorhizic root system, which is found in monocotyledones, is characterized by the development of many adventitious roots in parallel to the primary root (Atkinson et al., 2014, Osmont et al., 2007). In contrast to lateral roots, adventitious roots (ARs) are formed from above-ground organs such as hypocotyls, stems and leaves. Unlike lateral roots, which originate from pericycle cells, adventitious roots originate from cambial or other meristematic cells (Leguéa et al., 2014). The majority of the root system in maize and rice the majority of the root system is formed from postembryonic shoot-borne roots. All the root types can branch by forming lateral roots, giving the root system a bushy appearance. Maize forms additional embryogenic roots, which emerge from the scutellar node and are called 
seminal roots. Primary roots of monocotyledons are often also referred to seminal roots (Figure 1) (Dolan et al., 1993; Osmont et al., 2007; Atkinson et al., 2014).

Root System Architecture (RSA) - In the context of biology, the word "architecture" usually stands for the spatial configuration of some complex assemblage of subunits, with the implication that the overall configuration has some functional significance (Lynch, 1995). RSA has been described as the spatial configuration of a root system in the soil and the term RSA is generally used to describe the shape and structure of root systems (De Dorlodot et al., 2007).

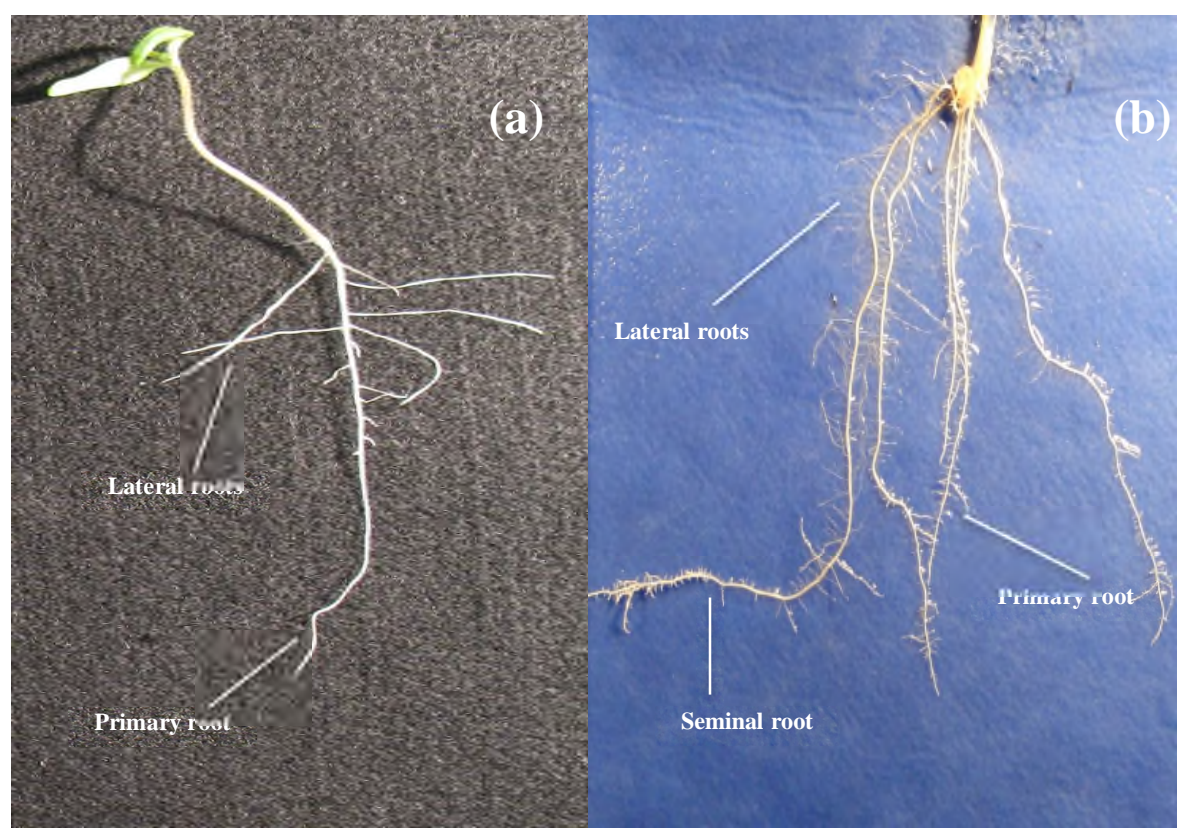

Figure 1. Tomato and rice root system with the major root types indicated. Macroscopic view of 8 day old Tomato (a) and 10 day old rice root system (b).

RSA is known to be highly plastic and strongly affected by environmental conditions (Deak and Malamy, 2005). The primary root is the origin of the plant root system, which is established during embryogenesis. However, the adult plant's root system is made up also of lateral roots and adventitious roots, which form post-embryonically. The number and position of lateral roots is determined by the postembryonic decisions, which affect the size and overall architecture of the root system (Malamy, 2005; Macgregor et al., 2008). RSA affects 
plant productivity because the main soil resources are heterogeneously distributed in the soil, so that the spatial deployment of roots will determine the amount of water and nutrients available to the plant, and can be an important factor in the plant's ability to compete for soil resources (Lynch, 1995). Depending on soil composition, differences in RSA may affect the ability to compete for soil resources. RSA can be modulated in several ways: through promotion or inhibition of primary root growth, through growth of lateral roots, through the formation of adventitious roots and through an increase in root hairs (Osmont et al., 2007).

In the past two decades, studies in Arabidopsis have provided detailed insight into root structure. Arabidopsis roots consist of concentric layers of epidermis, cortex, endodermis and pericycle that surround the vascular tissue in the middle of the root. The epidermal cells consist of two types of cells: root hair cells and non root-hair cells. Lateral roots in Arabidopsis originate from pericycle founder cells located opposite xylem poles (Péret et al., 2009). It has been suggested that the pericycle cells that will initiate lateral root primordia continue or stay at least competent to divide after leaving the root apical meristem (RAM) (Dolan et al., 1993; Beeckman et al., 2001). Later on it was shown that the decision to recruit pericycle cells for lateral root formation is taken in the basal meristem, a zone behind the primary root apical mesristem (De Smet et al., 2007). The initiation of lateral roots occurs in the differentiation zone and happens when either one or two pericycle founder cells divide anticlinally to give rise to $8-10$ cell layer stage 1 primordia. The cells then divide in a periclinal plane to give rise to another layer. Afterward, daughter cells continue to divide in periclinal or anticlinal planes to create a dome-shaped primordium (spanning stages III-VII) that eventually emerges (at stage VIII) from the parental root (Malamy and Benfey, 1997; Casimiro et al., 2003; Péret et al., 2009).

Though Arabidopsis has been an excellent model for root/lateral root development it is also becoming clear that many plant species show distinctive cellular aspects that are different from Arabidopsis (Ron et al., 2013). For example, Arabidopsis contains only four QC cells whereas most monocot and dicot species contain a greater number of QC cells (Jiang et al., 2003). To date the regulatory mechanisms controlling this diversity in QC cell number are completely unknown. Additionally, most monocot and dicot species unlike Arabidopsis contain numerous cortex layers (Dolan et al., 1993). Even within in the same genus, there could be significant developmental differences. The wild tomato species Solanum pennellii 
adapted to growing at high altitudes in often near desert conditions in South America contains one less cell layer in the roots compared to the cultivated Solanum lycopersicum, $c v$. M82. This extra, complete layer in M82 was found throughout the root and was derived from a cortex- endodermis initial in contrast to a middle cortex layer (Ron et al., 2013).

\section{RSA is controlled by developmental cues and the environment}

Genetically identical plants can differ in RSA, depending on their macro- and microenvironment. Factors include nutrient and water availability and distribution status, soil density, salinity and temperature, and interaction with micro-organisms. Even though this plasticity is well documented, the molecular mechanisms underlying it are yet poorly understood (Zhang et al., 1999; Deak and Malamy, 2005; Nacry et al., 2005; Osmont et al., 2007). Nutrients such as nitrate, phosphate, potassium, sulphate and iron can act as signals that roots can be perceived and respond to. Among all nutrients, the quantity of nitrogen $(\mathrm{N})$ and phosphorus (P), have been found to have the greatest effect on RSA (Forde and Lorenzo 2001; Linkohr et al., 2002; López-Bucio et al., 2003). The changes in the internal and external concentration of nutrients can affect important developmental processes, such as root-hair formation, primary root growth and lateral root formation. Abiotic factors that influence RSA can also include light, which can act as a major positive regulator of root branching (Osmont et al., 2007). Here we discuss the role of water and individual nutrients and then bring these abiotic factors together with the role of developmental cues such as plant hormones to control RSA.

Water is the most limiting resource for agriculture, and therefore irrigation has become an important contributor to improved yields. About 83 percent of the water that is consumed (that is, not recycled) is devoted to irrigation (Boyer, 1982). The amount of water required varies greatly between different agricultural types and climatic regions (Morison et al., 2008). In arid and semi-arid environments, water availability varies greatly with soil depth and season and therefore root architecture has a key role in determining the productivity in these environments. Some desert root systems have been identified, with deep taproots, shallow lateral roots (Lynch, 1995). Even though most crop species have been domesticated in less extreme environments, there are wild crop progenitors which are adapted to a wide range of environments including high altitude and desert habitats (Boyer, 1982). The capacity of a root 
system for water uptake is important for crop productivity, and this capacity depends primarily on the degree to which the root extends its absorption area. The absorption area, which exhibits genetic variation, is determined by RSA. To date, many studies have reported quantitative trait loci (QTLs) for rice root system characteristics such as mass and depth. However, very little has been clarified about how these QTLs control root system growth at the detailed morphological level (Horii et al., 2006). Therefore, identification and deeper understanding genes regulating these root traits will be crucial for developing strategies for future crop improvement programmes. Cloning and characterization of DRO1 in rice is one such example. DRO1 gene regulates root angle in rice and introduction of DRO1 gene in shallow rooted and drought sensitive but commercially important IR64 variety resulted in deeper roots and improved drought tolerance (Uga et al., 2013).

Nitrogen $(N)$ availability is a major factor limiting growth and development of plants (Postma et al., 2014; Yu et al., 2014; Linkohr et al., 2002; Kraiser et al., 2011). In the biosphere, $\mathrm{N}$ is available in different forms, such as inorganic molecular $\mathrm{N}_{2}$, ammonium or nitrogen oxides, and the organic N (e.g. amino acids). Plants can use all these forms with the proviso that the direct use of molecular $\mathrm{N}_{2}$ is available only to the plant species living in symbiosis with nitrogen fixing bacteria (Wiren et al., 1997; Zhang et al., 1999). Nitrate has an important impact on LR development, and when the supply of nutrients in soil or media is not uniform, LRs tend to proliferate in a nutrient-rich zone. This has been observed with several different nutrients and many plant species (Ogawa et al., 2014; Robinson, 1994; Casimiro et al., 2003). Genetic and molecular approaches have revealed that nitrogen availability affects lateral root development by three different nitrogen-related regulatory mechanisms: (1) a localized stimulatory effect that acts mainly on the elongation of LR, which is more obvious when plants grown on low nitrate are treated with a localized nitrate supply and is mediated by a putative MADS-box transcription factor, ANR1 (ARABIDOPSIS NITRATE REGULATED 1) (Robinson, 1994; Zhang et al., 1999; LópezBucio et al., 2003); (2) the inhibitory effect, which can be observed when plants are grown on a medium with a uniformly high nitrate concentration immediately after the emergence of the lateral root primordium from the parent root (Zhang et al., 1999; Zhang and Forde, 2000); and (3) inhibition by a high sucrose-to-nitrogen $(\mathrm{C}: \mathrm{N})$ ratio, which leads to a dramatic 
repression of LR development (Malamy and Ryan, 2001; Casimiro et al., 2003; Malamy, 2005).

Phosphate (P) After N, P is quantitatively the most important nutrient for plant growth (Vance et al., 2003; Lambers et al., 2006). It is an essential non-renewable inorganic nutrient for all living organisms; making up about $0.2 \%$ of a plant's dry weight as a fundamental component that is present in key organic molecules such as DNA, RNA, ATP, NADPH, and membrane phospholipids, and, therefore, plants cannot grow without a reliable supply of this nutrient (Schachtman et al., 1998). P plays a very important role in most of plant developmental pathways such as energy generation, nucleic acid synthesis, photosynthesis, glycolysis, respiration, membrane synthesis and stability, enzyme activation/inactivation, redox reactions, signaling pathways, carbohydrate metabolism, and nitrogen fixation (Lambers et al., 2006). Though $\mathrm{P}$ is prevalent in soil, it is not in its bioavailable form thus making it a major limiting factor for plant growth (Hinsinger, 2001). It can be taken up by plants as inorganic phosphate $(\mathrm{Pi})$ forms $\mathrm{H}_{2} \mathrm{PO}_{4}{ }^{-}$and $\mathrm{HPO}_{4}{ }^{2-}$, which occur in soil solutions at very low concentrations $(0.1-10 \mu \mathrm{M})$ (Vance et al., 2003).

To cope with inadequate Pi supply, plants adapt by increasing Pi uptake and recycling through a combination of growth, developmental and metabolic responses (Ogawa et al., 2014; Ticconi and Abel, 2004; Tran et al., 2010). One of the key plant responses to low soil $\mathrm{Pi}$ includes the secretion of organic acids into the rhizosphere to aid in mobilizing bound organic phosphates which is one of the primary mechanisms facilitating the release of orthophosphate (Tran et al., 2010). Plants in some families (e.g. Proteaceae, Casuarinaceae, Fabaceae and Myricaceae) can form dense clusters of lateral roots called 'cluster roots', an adaptation in nutrient-poor soil (Neumann and Martinoia, 2002; Lamont, 2003; Shane and Lambers, 2005). Another adaptation of plants to low phosphorus availability includes symbioses with microbes, notably mycorrhizal fungi (arbuscular mycorrhizae or ectomycorrhizae) (Bolan, 1991; Péret et al., 2011). Developmental responses to inadequate Pi supply can be dramatic changes in RSA such as an arrest of primary root elongation, an increase in lateral root formation and emergence, and an increase in root hair proliferation (Bai et al., 2013; Péret et al., 2011; Bates and Lynch, 1996). When growing with insufficient $\mathrm{Pi}$, RSA changes, resulting in a shallower root system bearing more and longer lateral roots as well as denser root hairs. One of the key transcription factors regulating phosphate 
starvation response is PHR1 (phosphate starvation response1). Recently it has been shown that a nuclear protein SPX1 regulates PHR1 activity (Puga et al., 2014). Auxin is also a key regulator of root and lateral root development and plays a key role under $\mathrm{P}$ starvation conditions (Deb et al., 2014).

\section{Control of Root Development by Hormones crosstalk}

In the nineteenth century, Charles Darwin demonstrated that numerous plant growth processes are regulated by "substances" that move from one part of the plant to another. Almost a century later scientists know that those "substances" are small molecules derived from various essential metabolic pathways which are called plant hormones or plant growth regulators (Santner et al., 2009). Auxin, abscisic acid (ABA), cytokinin, gibberellin and ethylene are the 5 'classical' phytohormones identified during the first half of the twentieth century; all can affect root growth. Moreover, several additional hormones such as brassinosteroids, jasmonate, salicylic acid, nitric oxide and strigolactones have been recognized recently (Santner and Estelle, 2009), and some have been shown to have an impact on the root growth. These plant hormones, which regulate plant growth and development and mediate responses to external environmental stimuli, are small, naturally occurring substances with very diverse chemical natures and structures (Santner and Estelle 2009; Santner et al., 2009; Wolters and Jürgens, 2009; Garay-Arroyo et al., 2012).

Auxin modulates several processes such as the response to light and gravity, control of root and shoot architecture, organ patterning, vascular development and growth in tissue culture (Cho et al., 2014; Woodward and Bartel, 2005; Benková and Hejátko, 2009; Santner and Estelle, 2009; Rodriguez-Villalon and Hardtke, 2014). Auxin plays a crucial role in regulating several key root traits including root angle, root length, root density and is also required for both initiation and emergence of lateral roots (Péret et al., 2009; Fukaki and Tasaka, 2009; Péret et al., 2012; Petricka et al., 2012; Laskowski, 2013; Lavenus et al., 2013). Application of exogenous auxin increases the number of LRs whereas inhibition of auxin transport decreases the number of LRs, indicating a positive role for auxin during LR formation (Casimiro et al., 2001; Nibau et al., 2008; Sun et al., 2009).

Indole-3-acetic acid (IAA), the major form of auxin in higher plants is predominantly synthesized in the shoot apex but it is now known that IAA can also be synthesized in the 
roots. It has been shown in Arabidopsis that the emergence of lateral root primordia (LRP) appears to be dependent on shoot-derived auxin in young seedlings (4 to 7 day old) but not in older (7 to 10 day old) seedlings. (Bhalerao et al., 2002; Ljung et al., 2005; Swarup et al., 2008). Auxin-induced growth responses in roots have been shown to be the result of downstream changes in expression of several genes including auxin transporters such as LAX3 and cell wall-remodeling enzymes such as pectate lyase, pectin methyl esterase, $\alpha$ expansin (Swarup et al., 2008, Lee et al., 2012), and $\beta$-xylosidase genes (Neuteboom et al., 1999; Laskowski et al., 2006). Interestingly, the pectin in the newly forming lateral roots was mainly methylated whilst that in the overlying cells of the parent root was demethylated. This could explain why the LRP is protected from cell wall degradation during emergence (Laskowski et al., 2006; Lavenus et al., 2013). All together these results suggest expression of cell-wall remodeling genes is triggered in the presence of auxin in the overlaying cells that will facilitate primordium emergence through the outer tissues (Swarup et al., 2008, Péret et al., 2012). Recently auxin has also been shown to affect lateral root emergence by affecting regulation of aquaporins. These facilitate water movement across cell membranes and auxin appears to repress aquaporin expression in the LRP and overlying tissues thus regulating tissue hydraulics to promote lateral root emergence (Péret et al., 2012). The level of auxin concentration in the root tissue can be modulated by nutrient status. Arabidopsis seedlings transferred from high nitrate $(50 \mathrm{mM})$ to low nitrate concentrations $(0.1 \mathrm{mM})$, show an increase in auxin concentration compared to plants grown continuously in high nitrate. The high level of auxin can be correlated with the release of LRs from high nitrate inhibition when transferred to low nitrate. This may suggest that high nitrate supply might be inhibiting auxin biosynthesis or its translocation from shoot to roots (Vidal and Gutiérrez, 2008). Besides auxin, ABA has also been associated with high nitrate repression of LR growth in an auxin independent pathway (De Smet et al., 2006).

Cytokinins are a class of plant hormones that play positive and negative regulatory roles in many aspects of plant growth and development. They stimulate the formation and activity of shoot meristems, retard leaf senescence, inhibit root growth and branching, and play a role in seed germination and stress responses. They also appear to mediate a number of light regulated processes including chloroplast differentiation (Werner et al., 2001; Werner et al., 2003). CKs antagonize auxin in many processes including their effect on LR development 
where cytokinins suppress lateral root formation. Transgenic Arabidopsis plants with decreased cytokinins levels have been reported to display increased root branching and also enhanced primary root growth (Osmont et al., 2007). Cytokinins receptor mutants cre 1-2 and the ahk2-5 ahk3-7 double mutant show longer primary roots and increased number of lateral roots (Riefler et al., 2006). Similarly, transgenic Arabidopsis plants overexpressing AtCKX (Cytokinin oxidase/dehydrogenase) show an increase in primary root length as well as increased numbers of lateral and adventitious roots (Beemster and Baskin, 2000; Werner et al., 2001; Werner et al., 2003). This behavior has also been shown in rice, where cytokinin has an inhibitory effect on LR initiation and stimulatory effect on LR elongation (Debi et al., 2005). It has been demonstrated that cytokinins regulate early processes involving the lateral root founder cells to disrupt lateral root initiation (Laplaze et al., 2007; Bishopp et al., 2011). The inhibitory lateral root initiation effect of cytokinins can be explained because exogenous Cytokinins block the G2 to M transition in pericycle founder cell activation (Li et al., 2006). The cytokinins biosynthesis and signalling mutants show a higher number of abnormally close LRPs in comparison to wild type plants which can suggest that endogenous cytokinins may be involved in the control of LRP spacing by preventing new LRs to initiate in close proximity to already existing LRPs (Bielach et al., 2012; Lavenus et al., 2013). Like Arabidopsis, the legume Medicago truncatula also uses cytokinins signalling to inhibit LR formation. RNA interference of the cytokinins receptor homolog Cytokinin Response1 (MtCRE1) led to CK-insensitive roots, which showed an increased number of lateral roots indicating a common role for cytokinins in higher plant LR formation (Gonzalez-Rizzo et al., 2006; Fukaki and Tasaka, 2009). In rice also it has been shown that cytokinins control crown root formation (Gao et al., 2014). Like auxin cytokinins are also known to regulate root system architecture in response to environmental cues (Ramireddy et al., 2014).

Both auxin and cytokinins coordinate their activities to regulate various aspects of plant growth and development. In dominant ren $1-D$ mutants crown root formation is promoted by rice cytokinin oxidase/dehydrogenase gene $O s C K X 4$ by mediating the interaction between cytokinin and auxin (Gao et al., 2014). In Arabidopsis, cytokinins have been shown to repress protoxylem cell specification but do not block xylem pole pericycle cell fate. Cytokinins did not affect the perception of auxin in lateral root founder cells whereas they block lateral root initiation in lateral root founder cells by inhibiting auxin-induced cell fate 
respecification by down regulating PIN gene expression (Laplaze et al., 2007). Merhavy et al., (2014) recently demonstrated a novel cytokinin-driven polarization mechanism that causes a rapid auxin stream redirection in developmental processes such as lateral root organogenesis, in which a gradual PIN polarity switch defines the growth axis of the newly formed organ. They show that auxin efflux transporter PIN1 depletion is enhanced by cytokinin at specific polar domains, thus rearranging the cellular PIN polarities and directly regulating the auxin flow direction (Mehravy et al., 2011; Merhavy et al., 2014).

Gibberellins (GAs) affect a wide range of plant growth, development, and environmental responses, including seed germination, stem elongation, leaf expansion, pollen maturation, induction of flowering and fruit development (Fleet and Sun, 2005; Ueguchi-Tanaka et al., 2007). GAs also foster root development and regulate root growth by controlling cell proliferation and elongation (Fu and Harberd, 2003; Ubeda-Tomás et al., 2008; UbedaTomás et al., 2009; Achard et al., 2009; Garay-Arroyo et al., 2012). The GA-deficient gal-3 Arabidopsis mutant has shorter primary roots that can be rescued by GA addition indicating that GA affects primary root growth (Fu and Harberd, 2003). Similarly in Poplar GAdeficient and GA-insensitive mutants show an increase in LR density and elongation, whereas enhanced GAs levels either in vivo or in vitro inhibited LR development (Gou et al., 2010).

The ability to increase root growth is important for newly germinated seedlings so they can rapidly take up water and nutrients after emerging from their seed coat and also have a better anchorage in the soil (Achard et al., 2009; Ubeda-Tomás et al., 2009; Ubeda-Tomás et al., 2012). The endodermis appears to be the primary responsive tissue for GA regulated root growth (Ubeda-Tomás et al., 2008, Ubeda-Tomás and Bennett, 2010). It has been shown that both GA biosynthesis and the GA response pathway are subject to regulation by auxin $(\mathrm{Fu}$ and Harberd, 2003). It has been demonstrated that shoot-derived auxin interacts with GA signals to regulate the levels of DELLA repressors. In addition, activity of enzymes involved in GA biosynthesis is dependent on the polar auxin transport (Fu and Harberd, 2003).

Brassinosteroids (BRs) are a group of plant-oristeroidal hormones with a wide range of biological activity and are essential for normal plant development. BRs are involved in several aspects of plant development, including the stimulation of cell division and 
elongation, vascular system differentiation, leaf development, bending, reproductive development, photomorphogenesis and root development. They are also involved in resistance responses against various abiotic and biotic stresses (Clouse and Sasse, 1998; Müssig et al., 2003; Divi and Krishna, 2009; Clouse, 2011). Almost 70 BRs have been identified in plants, with Brassinolide (BL) being the most biologically active (Fujioka and Yokota, 2003; Bajguz, 2007; Wang et al., 2009). Genetic and pharmacological studies have revealed that BRs promote root growth (Li et al., 2002; Müssig et al., 2003; Du et al., 2012). Work in Arabidopsis has revealed that BRs are required for the promotion of cell expansion and cell division in meristematic root cells and that balanced BR signaling is needed for the optimal root growth (González-García et al., 2011; Hacham et al., 2011).

Both BRs and auxin influence plant development and overlapping transcriptional responses to these phytohormones imply an interaction between the two hormonal pathways. It has been shown that in Arabidopsis roots, BREVIS RADIX $(B R X)$, which is a gene required for optimal root growth is involved in mediating the interaction BRs and auxin interaction. $B R X$ belongs to a plant-specific gene family that encodes proteins that are predicted to regulate transcription (Mouchel, 2004; Briggs et al., 2006; Mouchel et al., 2006). The Arabidopsis brx mutant has a root-specific deficiency of brassinosteroid. Interestingly, this deficiency affects the root expression level of approximately $15 \%$ of all Arabidopsis genes, however the transcriptome profile can be restored to wild type level by brassinosteroid treatment (Mouchel et al., 2006). This work indicates that Auxin strongly induced BRX expression while brassinolide mildly repressed BRX expression, suggesting that BRX acts at the centre for maintaining brassinosteroid levels to permit optimal auxin action (Mouchel et al., 2006). Recently it has been proposed that BRs may also regulate root growth in $\mathrm{P}$ deficient environment (Singh et al., 2014).

Abscisic Acid (ABA) regulates many aspects of plant growth and development including embryo maturation, seed dormancy, germination, seedling growth, lateral root development, cell division and elongation, transition from vegetative to reproductive phase and responses to environmental stresses such as drought, salinity, cold, pathogen attack and UV radiation (Zeevaart and Creelman, 1988; Finkelstein et al., 2002; Chinnusamy et al., 2008). ABA has been shown to affect root elongation in a dose dependent manner, where exogenously applied ABA promotes root elongation at lower concentrations $(0.1 \mathrm{mM})$ but inhibits root growth at 
concentrations above $1.0 \mathrm{mM}$ (Ghassemian et al., 2000; Garay-Arroyo et al., 2012). It has been reported that exogenous $\mathrm{ABA}$ also inhibits lateral root development in an auxinindependent manner, as the inhibitory effect of $\mathrm{ABA}$ could not be rescued by either exogenous auxin application or elevated auxin synthesis (Beaudoin et al., 2000; De Smet et al., 2003). Genetic evidence also supports a role for ABA in regulating root growth. SNF1RELATED PROTEIN KINASE2.2 (SnRK2.2) and SnRK2.3 are key protein kinases that mediate a major part of ABA signaling in Arabidopsis and the snrk2.2 snrk2.3 double mutant show strong ABA-insensitive phenotypes in seed germination and root growth inhibition (Fujii et al., 2007).

Interestingly, $\mathrm{ABA}$ has a key role in mediating the inhibitory effects of $\mathrm{NO}_{3}{ }^{-}$on $\mathrm{LR}$ formation. LR numbers are notably reduced in four ABA synthesis mutants (aba1-1, aba2-3, aba2-4 and aba3-2) and two ABA-insensitive mutants (abi4 and abi5) (Signora et al., 2001; De Smet et al., 2006). Other hormones such as auxin have been proposed to act as the longrange signal from shoot to root that mediates high nitrate inhibition of LR growth just after their emergence (Forde, 2002; Walch-Liu et al., 2006).

Ethylene is a plant hormone known to play a central role in several physiological processes, such as leaf and flower senescence, abscission of organs, flower initiation, fruit ripening, and seed germination and it also plays a crucial role during root development and root hair differentiation (Clark et al., 1999; Le et al., 2001; Růzicka et al., 2007; Swarup et al., 2007). Swarup et al., 2007 show that in Arabidopsis ethylene inhibits root growth by regulating the elongation of cells that leave the RAM (root apical meristem) and inhibition of root growth by ethylene is mediated via auxin. This is further supported by studies in tomato where ethylene receptor mutation Never-ripe $(\mathrm{Nr})$ show increased root mass but fewer adventitious roots (Clark et al., 1999). Treatment with auxin increased adventitious root formation on vegetative stem cuttings of wild-type plants but not in $\mathrm{Nr}$ plants. Reduced adventitious root formation has also been observed in ethylene-insensitive transgenic petunia plants suggesting that the effect of auxin on adventitious rooting is influenced by ethylene (Clark et al., 1999).

Ethylene has also been demonstrated to affect cell division in the quiescent centre (QC) cells and is likely to be involved in root meristem maintenance (Ortega-Martínez et al., 2007). Manipulation of the ethylene pathway genetically or chemically affected the division activity 
of the QC. Plants with elevated level of ethylene such as eto1 mutants show QC cell division independently of auxin and without interfering with QC cell fate (Ortega-Martínez et al., 2007; Thomann et al., 2009).

Strigolactones $(S L S)$ are hormones that regulate many aspects of plant development and in 2008 were identified as being responsible for inhibition of shoot branching (Beveridge, 2014; Bennett and Leyser, 2014); since then rapid progress has been made in understanding their biology. SLs are derived from cleavage of carotenoids and 15 strigolactones have been structurally characterized. They promote root-hair elongation and increase cell numbers in the primary-root meristem while suppressing lateral-root formation under conditions of sufficient phosphate, but they induce it under limiting phosphate (Kapulnik et al., 2014; Koren et al., 2013). They also suppress outgrowth of preformed axillary buds in the shoot, induce secondary growth in the stem, suppress adventitious-root formation and are involved in determining plant height (Beveridge, 2014; Koltai, 2014). In Medicago truncatula it has been shown that the application of the synthetic strigolactone analogue GR24 has an inhibitory effect on the lateral root density (De Cuyper et al., 2014). The biosynthetic and signaling pathways of SLs have been reasonably well understood by identification of defective genes from branching mutants of several plant species including Arabidopsis max (more axillary growth) mutants, pea rms (ramosus) mutants, petunia dad (decreased apical dominance) mutants and rice $d$ (dwarf) mutants (Germain et al., 2013; Zheng et al., 2014).

\section{Conclusion}

Crop production must double by 2050 to keep pace with global population growth (Lavenus et al., 2014). One way to reduce the negative impact of climate change on yield is to manipulate RSA in favour of improved distribution of roots in the soil to enhance water and nutrient uptake. Advances in root phenotyping and imaging using non invasive approaches such as X-ray computed tomography (Bao et al., 2014) and magnetic resonance imaging (Metzner et al., 2014) are very promising and are likely to provide better understanding of RSA. Using X-ray computed tomography recently Bao et al., (2014) revealed a novel hydropatterning mechanism highlighting the importance of these non invasive approaches to study RSA. Deeper understanding of RSA in soil and how RSA responds to environment signals such as changes in nutrient and water availability in soil and interaction with soil 
microflora will be crucial. These signals act through distinct signal transduction pathways involving a plethora of intrinsic factors including not only hormones as discussed above but also other signals such as microRNAs (Sorin et al., 2014), NO (Correa-Aragunde et al., 2004) and ROS (Manzano et al., 2014). However, molecular connections between these pathways are less understood, and it remains an outstanding question how different signaling pathways coordinately regulate RSA. Deeper understanding of the molecular mechanisms controlling key root traits will be crucial for developing strategies for future crop improvement programmes. Accurate phenotyping, modelling and input from farmers and breeders will help define ideal RSA for different crops and target environments and will result in the development of crops with improved water and nutrient uptake efficiency to improve yield and will be a big step forward towards meeting challenges of increasing future food demand in an environmentally friendly and sustainable manner.

\section{Acknowledgements:}

Fereshteh Malekpoor Mansoorkhani is funded by the UK Biotechnology and Biological Sciences Research Council (BBSRC) grant number BB/L019655/1 awarded to Professor Graham Seymour and Professor Malcolm Bennett. Dr Andrew J Thompson is funded by BBSRC grant BB/L01954X/1. We would like to thank Professor Malcolm Bennett for useful discussions during the preparation of the review. We would like to thank N. Czyzewicz for the rice root picture. 


\section{References}

Achard, P., Gusti, A., Cheminant, S., Alioua, M., Dhondt, S., Coppens, F., Beemster, G.T.S., Genschik, P. (2009) Report gibberellin signaling controls cell proliferation rate in Arabidopsis. Current Biology, 19, 1188-1193.

Atkinson, J.A., Rasmussen, A., Traini, A., Voß, U., Sturrock, C., Mooney, S.J., Wells, D., Bennett, M.J (2014) Branching Out in Roots: Uncovering Form, Function, and Regulation. Plant Physiology, 166, 538-550.

Bao, Y., Aggarwal, P., Neil E. Robbins, N.E., Sturrocke, C.J., Thompsone, M.C., Tanb, H.Q., Tham, C., Duan, L., Rodriguez, P.L., Vernoux, T., Mooney, S.J., Bennette, M.J., Dinneny, J.R. (2014) Plant roots use a patterning mechanism to position lateral root branches toward available water. Proceedings of the National Academy of Sciences, 111, 9319-9324.

Bai, H., Murali, B., Barber, K., Wolverton, C. (2013) Low phosphate alters lateral root setpoint angle and gravitropism. American Journal of Botany, 100, 175-182.

Bajguz, A. (2007) Metabolism of brassinosteroids in plants. Plant Physiology and Biochemistry, 45, 95-107.

Bates, T.R., Lynch, J.P. (1996) Stimulation of root hair elongation in Arabidopsis thaliana by low phosphorus availability. Plant, Cell and Environment, 19, 529-538.

Beaudoin, N., Serizet, C., Gosti, F., Giraudat, J. (2000) Interactions between abscisic acid and ethylene signaling cascades. Plant Cell, 12, 1103-1115.

Beeckman, T., Burssens, S., Inzé, D. (2001) The peri-cell-cycle in Arabidopsis. Journal of Experimental Botany, 52, 403-411.

Beemster, G.T., Baskin, T.I. (2000) Stunted plant 1 mediates effects of cytokinin, but not of auxin, on cell division and expansion in the root of Arabidopsis. Plant Physiology, 124, $1718-2177$.

Benková, E., Hejátko, J., (2009) Hormone interactions at the root apical meristem. Plant Molecular Biology, 69, 383-396. 
Bennett, T., Leyser, O. (2014) Strigolactone signalling: standing on the shoulders of DWARFs. Current Opinion in Plant Biology, 22, 7-13.

Beveridge, C.A. (2014) Strigolactones. Current Biology, 24, 987-988.

Bielach, A., Podlesáková, K., Marhavy, P., Duclercq, J., Cuesta, C., Müller, B., Grunewald, W., Tarkowski, P., Benková, E. (2012) Spatiotemporal regulation of lateral root organogenesis in Arabidopsis by cytokinin. Plant Cell, 24, 3967-3981.

Bishopp, A., Benková, E., Helariutta, Y. (2011) Sending mixed messages: auxin-cytokinin crosstalk in roots. Current Opinion in Plant Biology, 14, 10-16.

Bolan, N.S. (1991) A critical review on the role of mycorrhizal fungi in the uptake of phosphorus by plants. Plant Soil, 134, 189-207.

Boyer, J.S. (1982) Plant productivity and environment. Science, 218, 443-448.

Briggs, G.C. Brigg, M.F., Hardtke, C.S. (2006) Characterization of the plant-specific BREVIS RADIX gene family reveals limited genetic redundancy despite high sequence conservation. Plant Physiology, 140, 1306-1316.

Casimiro, I., Marchant, A., Bhalerao, R.P., Beeckman, T., Dhooge, S., Swarup, R., Graham, N., Inzé, D., Sandberg, G., Casero, P.J. (2001) Auxin transport promotes Arabidopsis lateral root initiation. Plant Cell, 13, 843-852.

Casimiro, I., Beeckman, T., Graham, N., Bhalerao, R., Zhang, H., Casero, P., Sandberg, G., Bennett, M.J. (2003) Dissecting Arabidopsis lateral root development. Trends in Plant Science, 8, 165-171.

Chaves, M.M., Maroco, J.P. and Pereira, J.S. (2003) Understanding plant responses to drought — from genes to the whole plant. Functional Plant Biology, 30, 239-264.

Chinnusamy, V., Gong, Z., Zhu, J.K. (2008) Abscisic acid-mediated epigenetic processes in plant development and stress responses. Journal of Integrative Plant Biology, 50, 11871195 . 
Cho, H, Ryu, H, Rho, S, Hill, K, Smith, S, Audenaert, D, Park, J, Han, S, Beeckman, T, Bennett, M.J., Hwang, D, De Smet, I, Hwang, I, 2014. A secreted peptide acts on BIN-2 mediated phosphorylation of ARFs to potentiate auxin response during lateral root development. Nature Cell Biology, 16, 66-76.

Clark, D.G., Gubrium, E.K., Barrett, J.E., Nell, T.A, Klee, H.J. (1999) Root formation in ethylene-insensitive plants. Plant Physiology, 121, 53-60.

Clouse, S.D., Sasse, J.M. (1998) BRASSINOSTEROIDS: Essential Regulators of Plant Growth and Development. Annual Review Plant Physiology and Plant Molecular Biology, 49, 427-451.

Clouse, S.D. (2011) Brassinosteroid signal transduction: from receptor kinase activation to transcriptional networks regulating plant development. Plant Cell, 23, 1219-1230.

Coudert, Y., Périn, C., Courtois, B., Khong, N.G. and Gantet, P. (2010) Genetic control of root development in rice, the model cereal. Trends in Plant Science 15, 219-226.

Deak, K.I., Malamy, J. (2005) Osmotic regulation of root system architecture. The Plant journal: for cell and molecular biology, 43, 17-28.

Debi B.R., Taketa, S., Ichii, M. (2005) Cytokinin inhibits lateral root initiation but stimulates lateral root elongation in rice (Oryza sativa). Journal of plant physiology, 162, 507-515.

Deb, S., Sankaranarayanan, S., Wewala, G., Widdup, E., Samuel, M.A. (2014) The S-Domain Receptor Kinase Arabidopsis Receptor Kinase2 and the U Box/Armadillo repeatcontaining E3 ubiquitin Ligase9 module mediates lateral root development under phosphate starvation in Arabidopsis. Plant Physiology, 165, 1647-1656.

De Cuyper, C., Fromentin, J., Yocgo, R.E., De Keyser, A., Guillotin, B., Kunert, K., Boyer, F.D., Goormachtig, S. (2014) From lateral root density to nodule number, the strigolactone analogue GR24 shapes the root architecture of Medicago truncatula. Journal of Experimental Botany, 65, 1-10.

Divi, U.K., Krishna, P. (2009) Brassinosteroid: a biotechnological target for enhancing crop yield and stress tolerance. New biotechnology, 26, 131-136. 
Dolan, L., Janmaat, K., Willemsen, V., Linstead, P., Poethig, S., Roberts, K., Scheres, B. (1993) Cellular organisation of the Arabidopsis thaliana root. Development, 119, 71-84.

De Dorlodot, S., Forster, B., Pagès, L., Price, A., Tuberosa, R., Draye, X. (2007) Root system architecture: opportunities and constraints for genetic improvement of crops. Trends in Plant Science, 12, 474-481.

De Smet, I., Signora, L., Beeckman, T., Inzé, D., Foyer, C.H., Zhang, H. (2003) An abscisic acid-sensitive checkpoint in lateral root development of Arabidopsis. Plant Journal, 33: $543-55$

De Smet, I., Zhang, H., Inzé, D., Beeckman, T. (2006) A novel role for abscisic acid emerges from underground. Trends in Plant Science, 11, 434-439.

De Smet, I., Tetsumura, T., De Rybel, B., Frey, N.F.D., Laplaze, L., Casimiro, I., Swarup, R., Naudts, M., Vanneste, S., Audenaert, D., Inzé, D., Bennett, M.J., Beeckman, T. (2007) Auxin-dependent regulation of lateral root positioning in the basal meristem of Arabidopsis. Development 134, 681-690.

Du, J., Yin, H., Zhang, S., Wei, Z., Zhao, B., Zhang, J., Gou, X., Lin, H., Li, J. (2012) Somatic embryogenesis receptor kinases control root development mainly via brassinosteroid-independent actions in Arabidopsis thaliana. Journal of Integrative Plant Biology, 54, 388-399.

Finkelstein, R.R., Gampala, S.S.L., Rock, C.D. (2002) Abscisic Acid Signaling in Seeds and Seedlings. The Plant Cell, 14, 15-45.

Fitter, A.H. (1987) An architectural approach to the comparative ecology of plant root systems. New Phytologist, 106, 61-77.

Fitter, A.H., Stickland, T.R., Harvey, M.L., Wilson, G.W. (1991) Architectural analysis of plant root systems. 1. Architectural correlates of exploitation efficiency. New Phytology, 118, $375-382$. 
Fleet, C.M., Sun, T. (2005) A DELLAcate balance: the role of gibberellin in plant morphogenesis. Current Opinion in Plant Biology, 8, 77-85.

Forde, B., Lorenzo, H. (2001) The nutritional control of root development. Plant Soil, 232, $51-68$.

Forde, B.G. (2002) Local and long-range signaling pathways regulating plant responses to nitrate. Annual Review of Plant Biology, 53, 203-224.

Fu, X., Harberd, N.P. (2003) Auxin promotes Arabidopsis root growth by modulating gibberellin response. Nature 421: 740-743.

Fujii, H., Verslues, P.E., Zhu, J.K. (2007) Identification of two protein kinases required for abscisic acid regulation of seed germination, root growth, and gene expression in Arabidopsis. Plant Cell, 19, 485-494.

Fujioka, S., Yokota, T. (2003) Biosynthesis and metabolism of brassinosteroids. Annual Review in Plant Biology, 54, 137-164.

Fukaki, H., Tasaka, M. (2009) Hormone interactions during lateral root formation. Plant Molecular Biology 69: 437-449.

Gao, S., Fang, J., Xu, F., Wang, W., Sun, X., Chu, J., Cai, B., Feng, Y., Chu, C. (2014) A cytokinin oxidase/dehydrogenase gene OsCKX4 integrates cytokinin and auxin signaling to control rice crown root formation. Plant Physiology, 165, 1035-1046.

Garay-Arroyo, A., De La Paz Sánchez, M., García-Ponce, B., Azpeitia, E., Alvarez-Buylla, E.R. (2012) Hormone symphony during root growth and development. Developmental dynamics, 241, 1867-1885.

Ghassemian, M., Nambara, E., Cutler, S., Kawaide, H., Kamiya, Y., McCourt, P. (2000) Regulation of abscisic acid signaling by the ethylene response pathway in Arabidopsis. Plant Cell, 12, 1117-1126. 
Germain, A.D.S, Bonhomme, S., Boyer, F.D., Rameau, C. (2013). Novel insights into strigolactone distribution and signallin. Current Opinion in Plant Biology, 16,583-589.

Gewin, V. (2010) An underground revelution. Nature, 466, 552-553.

Goh, T., Voß, U., Farcota, E., Bennett, M.J., Bishopp, A. (2013) Systems biology approaches to understand the role of auxin in root growth and development. Physiologia Plantarum, $151,73-82$.

González-García, M.P., Vilarrasa-Blasi, J., Zhiponova, M., Divol, F., Mora-García, S., Russinova, E., Caño-Delgado, A.I. (2011) Brassinosteroids control meristem size by promoting cell cycle progression in Arabidopsis roots. Development, 138, 849-859.

Gonzalez-Rizzo, S., Crespi, M., Frugier, F. (2006) The Medicago truncatula CRE1 cytokinin receptor regulates lateral root development and early symbiotic interaction with Sinorhizobium meliloti. Plant Cell, 18, 2680-2093.

Gou, J., Strauss, S.H., Tsai, C.J., Fang, K., Chen, Y., Jiang, X., Busov, V.B. (2010) Gibberellins regulate lateral root formation in Populus through interactions with auxin and other hormones. Plant Cell, 22, 623-639.

Hacham, Y., Holland, N., Butterfield, C., Ubeda-Tomas, S., Bennett, M.J., Chory, J., SavaldiGoldstein, S. (2011) Brassinosteroid perception in the epidermis controls root meristem size. Development, 138, 839-848.

Herder, G. Den, Van Isterdael, G., Beeckman, T., De Smet, I. (2010) The roots of a new green revolution. Trends in Plant Science, 15, 600-607.

Hinsinger, P. (2001) Bioavailability of soil inorganic P in the rhizosphere as affected by rootinduced chemical changes : a review. Plant and Soil, 273, 173-195.

Hochholdinger, F., Woll, K., Sauer, M., Dembinsky, D., (2004) Genetic dissection of root formation in maize (Zea mays) reveals root-type specific developmental programmes. Annals of Botany, 93, 359-368. 
Hochholdinger, F, and Tuberosa, R. (2009) Genetic and genomic dissection of maize root development and architecture. Current Opinion in plant biology, 12, 172-177.

Hodge, A., Berta, G., Doussan, C., Merchan, F., Crespi, M. (2009) Plant root growth, architecture and function. Plant Soil, 321, 153-187.

Horii, H., Nemoto, K., Miyamoto, N. and Harada, J. (2006) Quantitative trait loci for adventitious and lateral roots in rice. Plant Breeding, 125,198- 200.

Hue, T., Brenden, A.H., Plaxtona, W.C. (2010) Feeding hungry plants: The role of purple acid phosphatases in phosphate nutrition. Plant Science, 179,14-27.

Jiang, Y., Yang, B., Deyholos, M.K. (2009) Functional characterization of the Arabidopsis bHLH92 transcription factor in abiotic stress. Molecular Genetics and Genomics 282, $503-516$.

Kapulnik, Y., Koltai, H. (2014) Strigolactone involvement in root development, response to abiotic stress, and interactions with the biotic soil environment. Plant Physiology, 166, $560-569$.

Kraiser, T., Gras, D.E., Gutiérrez, A.G., González, B., Gutiérrez, R.A. (2011) A holistic view of nitrogen acquisition in plants. Journal of Experimental Botany, 62, 1455-66.

Koltai, H. (2014) Implications of non-specific strigolactone signaling in the rhizosphere. Plant Science, 225, 9-14.

Lambers, H., Shane, M.W., Cramer, M.D., Pearse, S.J., Veneklaas, E.J. (2006) Root structure and functioning for efficient acquisition of phosphorus: Matching morphological and physiological traits. Annals of Botany, 98, 693-713.

Lamont, B.B. (2003) Structure, ecology and physiology of root clusters - a review. Plant Soil, 248, 1-19.

Laplaze, L., Benkova, E., Casimiro, I., Maes, L., Vanneste, S., Swarup, R., Weijers, D., Calvo, V., Parizot, B., Herrera-Rodriguez, M.B., Offringa, R., Graham, N., Doumas, P., 
Friml, J., Bogusz, D., Beeckman, T., Bennett, M. (2007) Cytokinins act directly on lateral root founder cells to inhibit root initiation. Plant Cell, 19, 3889-3900.

Laskowski, M., Biller, S., Stanley, K., Kajstura, T., Prusty, R. (2006) Expression profiling of auxin-treated Arabidopsis roots: toward a molecular analysis of lateral root emergence. Plant Cell Physiology, 47, 788-792.

Laskowski, M., (2013) Lateral root initiation is a probabilistic event whose frequency is set by fluctuating levels of auxin response. Journal of Experimental Botany, 64, 2609-2617.

Lavenus, J., Goh, T., Roberts, I., Guyomarc'h, S., Lucas, M., De Smet, I., Fukaki, H., Beeckman, T., Bennett, M., Laplaze, L. (2013) Lateral root development in Arabidopsis: fifty shades of auxin. Trends in Plant Sciences, 18, 1-9.

Le, J., Vandenbussche, F., Van Der Straeten, D. and Verbelen, J.P. 2001. In the early response of Arabidopsis roots to ethylene, cell elongation is up- and down-regulated and uncoupled from differentiation. Plant Physiology, 125, 519-522.

Lee, H.W., Kim, M.J., Kim, N.Y., Lee, S.H., Kim, J. (2012) LBD18 acts as a transcriptional activator that directly binds to the EXPANSIN14 promoter in promoting lateral root emergence of Arabidopsis. Plant Journal, 16, 212-224.

Leguéa, V., Rigald, A., Bhalerao, R.P. (2014) Adventitious root formation in tree species: involvement of transcription factors. Physiologia Plantarum, 151, 192-198.

Li, X., Mo, X., Shou, H., Wu, P. (2006) Cytokinin-mediated cell cycling arrest of pericycle founder cells in lateral root initiation of Arabidopsis. Plant Cell Physiology, 47, 11121123.

Linkohr, B.I., Williamson, L.C., Fitter, A.H., Leyser, H.M.O. (2002) Nitrate and phosphate availability and distribution have different effects on root system architecture of Arabidopsis. Plant Journal, 29, 751-760.

Ljung, K., Hull, A.K., Celenza, J., Yamada, M., Estelle, M., Normanly, J. (2005) Sites and Regulation of Auxin Biosynthesis in Arabidopsis Roots. The Plant Cell, 17, 1090-1104. 
López-Bucio, J., Cruz-Ramírez, A., Herrera-Estrella, L. (2003) The role of nutrient availability in regulating root architecture. Current Opinion in Plant Biology, 6, 280287.

Lynch, J.P. (1995) Root Architecture and Plant Productivity. Plant Physiology, 109, 7-13.

Lynch, J.P. (2007) Roots of the second green revolution. Australian Journal of Botany, 55, $493-512$.

Lynch, J.P., Brown, K.M. (2012) New roots for agriculture: exploiting the root phenome. Philosophical Transactions of the Royal Society, 367, 1598-1604.

Macgregor, D.R., Deak, K.I., Ingram, P.A, Malamy, J.E. (2008) Root system architecture in Arabidopsis grown in culture is regulated by sucrose uptake in the aerial tissues. Plant Cell, 20, 2643-2660.

Malamy, J.E., Benfey, P.N. (1997) Organization and cell differentiation in lateral roots of Arabidopsis thaliana. Development, 124, 33-44.

Malamy, J.E., Ryan, K.S. (2001) Environmental Regulation of Lateral Root Initiation in Arabidopsis. Plant Physiology, 127, 899-909.

Malamy, J.E. (2005) Intrinsic and environmental response pathways that regulate root system architecture. Plant, Cell and Environment, 28, 67-77.

Manzano, C., Pallero-Baena, M., Casimiro, I., De Rybel, B., Orman-Ligeza, B., Van Isterdael, G., Beeckman, T., Draye, X., Casero, P., Del Pozo, J.C. (2014) The Emerging Role of reactive oxygen species signaling during lateral root development. Plant Physiology, 165, 1105-1119.

Marhavy, P., Bielach, A., Abas, L., Abuzeineh, A., Duclercq, J., Tanaka, H., Parezova, M., Petrasek, J., Friml, J., Kleine-Vehn, J., Benkova, E. (2011) Cytokinin modulates endocytic trafficking of PIN1 auxin efflux carrier to control plant organogenesis. Developmental Cell, 4, 796-804. 
Marhavy, P., Duclercq, J., Weller, B., Feraru, E., Offringa, R., Friml, J., Schwecheimer, C., Murphy, A., Benkova, E. (2014) Cytokinin controls polarity of PIN1-dependent auxin transport during plant organogenesis. Current Biology, 24, 1031-1037.

Metzner, R., Van Dusschoten, D., Bueler, J., Schurr, U., Jahnke, S. (2014) Below ground plant development measured with magnetic resonance imaging (MRI): exploiting the potential for non-invasive trait quantification using sugar beet as a proxy. Frontiers in Plant Science, 5, 1-11.

Montiel, G., Gantet, P., Jay-allemand, C. and Breton, C. (2004) Transcription factor networks. Pathways to the knowledge of root development. Plant Physiology, 136, $3478-3485$.

Morison, J.I.L., Baker, N.R., Mullineaux, P.M., Davies, W.J. (2008) Improving water use in crop production. Philosophical Transactions of the Royal Society, 363, 639-658.

Mouchel, C.F. (2004) Natural genetic variation in Arabidopsis identifies BREVIS RADIX, a novel regulator of cell proliferation and elongation in the root. Genes Development, 18, $700-714$.

Mouchel, C.F., Osmont, K.S., Hardtke, C.S. (2006) BRX mediates feedback between brassinosteroid levels and auxin signalling in root growth. Nature, 443, 458-461.

Müssig, C., Shin, G., Altmann, T. (2003) Brassinosteroids promote root growth in Arabidopsis. Plant Physiology, 133, 1261-1271.

Neumann, G., Martinoia, E. (2002) Cluster roots--an underground adaptation for survival in extreme environments. Trends in the Plant Sciences, 7, 162-167.

Neuteboom, L.W., Ng J.M., Kuyper, M., Clijdesdale, O.R., Hooykaas, P.J., Van der Zaal B.J. (1999) Isolation and characterization of cDNA clones corresponding with mRNAs that accumulate during auxin-induced lateral root formation. Plant Molecular Biology, 39, 273-287. 
Nacry, P., Canivenc, G., Muller, B., Azmi, A., Onckelen, H.V., Rossignol, M., Doumas, P. (2005) A role for auxin redistribution in the responses of the root system architecture to phosphate starvation in Arabidopsis. Plant Phisiology, 138, 2061-2074.

Ogawa, S., Selvaraj, M.G., Fernando, A.J., Lorieux, M., Ishitani, M., McCouch, S., Arbelaez, J.D. (2014) N- and P-mediated seminal root elongation response in rice seedlings. Plant and Soil, 375, 303-315.

Ortega-Martínez, O., Pernas, M., Carol, R.J., Dolan, L. (2007) Ethylene modulates stem cell division in the Arabidopsis thaliana root. Science, 317, 507-510.

Osmont, K.S., Sibout, R., Hardtke, C.S. (2007) Hidden branches: developments in root system architecture. Annual Review of Plant Biology, 58, 93-113.

Péret, B., De Rybel, B., Casimiro, I., Benková, E., Swarup, R., Laplaze, L., Beeckman, T., Bennett, M.J. (2009) Arabidopsis lateral root development: an emerging story. Trends in Plant Science, 14, 399-408.

Péret, B., Clément, M., Nussaume, L., Desnos, T. (2011) Root developmental adaptation to phosphate starvation: better safe than sorry. Trends in Plant Science, 16, 442-450.

Péret, B., Li, G., Zhao, J., Band, L.R., Voß, U., Postaire, O., Luu, D.T., Da Ines, O., Casimiro, I., Lucas, M., Wells D.M., Lazzerini, L., Nacry, P., King, J.I., Jensen, O.E., Schäffner, A.R., Maurel, C., Bennett, M.J. (2012) Auxin regulates aquaporin function to facilitate lateral root emergence. Nature Cell Biology, 14, 991-998.

Petricka, J.J., Winter, C.M., Benfey, P.N. (2012) Control of Arabidopsis root development. Annual Review of Plant Biology, 63, 563-590.

Postma, J.A., Dathe, A., Lynch, J.P. (2014) The optimal lateral root branching density for maize depends on nitrogen and phosphorus availability. Plant Physiology, 590-602.

Puga, M.I., Mateosa, I., Charukesia, R., Wang Z., Franco-Zorrillac, J.M., De Lorenzoa, L., Irigoyen, M.L., Masiero, S., Bustos, R., Rodríguez, J., Leyva, A., Rubio, V., Sommer, H., Paz-Ares, J. (2014) SPX1 is a phosphate-dependent inhibitor of PHOSPHATE 
STARVATION RESPONSE 1 in Arabidopsis. Proceedings of the National Academy of Sciences of the United States of America, 111, 14947-14952.

Ramireddy, E., Chang, L., Schmulling, T. (2014) Cytokinin as a mediator for regulating root system architecture in response to environmental cues. Plant Signaling \& Behaviour, 9, 27771-27775.

Raven, J.A. and Edwards, D. (2001) Roots: evolutionary origins and biogeochemical significance. Journal of Experimental Botany, 52, 381- 401.

Riefler, M., Novak, O., Strnad, M., Schmulling, T. (2006) Arabidopsis cytokinin receptor mutants reveal functions in shoot growth, leaf senescence, seed size, germination, root development and cytokinin metabolism. The Plant Cell, 18, 40-54.

Robinson, B.D. (1994) The responses of plants to non-uniform supplies of nutrients. New Phytologist, 127, 635-674.

Ron, M., Dorrity, M.W., De Lucas, M., Toal, T., Hernandez, R.I., Little, S.A., Maloof, J.N., Klibenstein, D.J., Brady, S.M. (2013) Identification of novel loci regulating interspecific variation in root morphology and cellular development in Tomato. Plant Physiology, 162, 755-768.

Royal society (2009) Reaping the benefits. ISBN:978-0-85403-784-1

Růzicka, K., Ljung, K., Vanneste, S., Podhorská, R., Beeckman, T., Friml, J. and Benková, E. 2007. Ethylene regulates root growth through effects on auxin biosynthesis and transportdependent auxin distribution. The Plant Cell, 19, 2197-2212.

Sánchez-Calderón, L., Ibarra-Cortés, M.E., Zepeda-Jazo, I. (2013) Root development and abiotic stress adaptation. In: K. VahdatiC. Leslie. Abiotic Stress - Plant Responses and Applications in Agriculture. pp. 135-167.

Santner, A., Calderon-Villalobos, L.I.A., Estelle, M. (2009) Plant hormones are versatile chemical regulators of plant growth. Nataure Chemical Biology, 5, 301-307. 
Santner, A., Estelle, M. (2009) Recent advances and emerging trends in plant hormone signalling. Nature, 459, 1071-1078.

Schachtman, D.P., Reid, R.J., Ayling, S.M. (1998) Update on Phosphorus Uptake Phosphorus Uptake by Plants : From Soil to Cell. Plant Phisiology, 116, 447-453.

Shane, M.W., Lambers, H. (2005) Cluster roots : A curiosity in context. Plant and Soil, 247, $101-125$.

Signora, L., De Smet, I., Foyer, C.H., Zhang, H. (2001) ABA plays a central role in mediating the regulatory effects of nitrate on root branching in Arabidopsis. The Plant Journal, 28, 655-662.

Singh, A.P., Fridman, Y., Friedlander-Shani, L., Tarkowska, D., Strnad, M., SavaldiGoldstein, S. (2014) Activity of the brassinosteroid transcription factors BRASSINAZOLE RESISTANT1 and BRASSINOSTEROID INSENSITIVE1-ETHYL METHANESULFONATE-SUPPRESSOR1/BRASSINAZOLE RESISTANT2 blocks developmental reprogramming in response to low phosphate availability. Plant physiology, 166, 678-688.

Sorin, C., Declerck, M., Christ, A., Blein, T., Ma, L., Lelandais-Briere, C., Njo, M., Fransiska Beeckman, T., Crespi, M., Hartmann, C. (2014) A miR169 isoform regulates specific NF-YA targets and root architecture in Arabidopsis. New Phytologist, 202, 1197-1211.

Sun, J., Xu, Y., Ye, S., Jiang, H., Chen, Q., Liu, F., Zhou, W., Chen de Dorlodot, R., Li, X., Tietz, O., Wu X, Cohen, J.D., Palme, K., Li, C. (2009) Arabidopsis ASAl is important for jasmonate-mediated regulation of auxin biosynthesis and transport during lateral root formation. The Plant Cell, 21, 1495-1511.

Swarup, R., Perry, P., Hagenbeek, D., Van Der Straeten, D., Beemster, G.T.S., Sandberg, G., Bhalerao, R., Ljung, K., Bennett, M.J. (2007) Ethylene upregulates auxin biosynthesis in Arabidopsis seedlings to enhance inhibition of root cell elongation. The Plant Cell, 19, 2186-2196. 
Swarup, K., Benková, E., Swarup, R., Casimiro, I., Péret, B., Yang, Y., Parry, G., Nielsen, E., De Smet, I., Vanneste, S., Levesque, M.P., Carrier, D., James, N., Calvo, V., Ljung, K., Kramer, K., Roberts, R., Graham, N., Marillonnet, S., Patel, K., Jones, J.D.G., Taylor, C.G., Schachtman, D.P., May, S., Sandberg, G., Benfey, P., Friml, J., Kerr, I., Beeckman, T., Laplaze, L., Bennett, M.J. (2008) The auxin influx carrier LAX3 promotes lateral root emergence. Nature Cell Biology, 10, 946-954.

Thomann, A., Lechner, E., Hansen, M., Dumbliauskas, E., Parmentier, Y., Kieber, J., Scheres, B., Genschik, P. (2009) Arabidopsis CULLIN3 genes regulate primary root growth and patterning by ethylene-dependent and -independent mechanisms. PLoS Genetics, 5, 1-14.

Ticconi, C.A., Abel, S., (2004) Short on phosphate: plant surveillance and countermeasures. Trends in Plant Sciences, 9, 548-455.

Tran, H.T., Hurley, B.A., Plaxton, W.C. (2010) Feeding hungry plants: The role of purple acid phosphatases in phosphate nutrition. Plant Sciences, 179, 14-27.

Ubeda-Tomás, S., Swarup, R., Coates, J., Swarup, K., Laplaze, L., Beemster, G.T.S., Hedden, P., Bhalerao, R., Bennett, M.J. (2008) Root growth in Arabidopsis requires gibberellin/DELLA signalling in the endodermis. Nature Cell Biology, 10, 625-628.

Ubeda-Tomás, S., Federici, F., Casimiro, I., Beemster, G.T.S., Bhalerao, R., Swarup, R., Doerner, P., Haseloff, J., Bennett, M.J. (2009) Gibberellin signaling in the endodermis controls Arabidopsis root meristem size. Current Biology, 19, 1194-1199.

Ubeda-Tomás, S., Bennett, M.J. (2010) Plant development: size matters, and it's all down to hormones. Current Biology, 20, 511-513.

Ubeda-Tomás, S., Beemster, G.T.S., Bennett, M.J. (2012) Hormonal regulation of root growth: integrating local activities into global behaviour. Trends in Plant Sciences, 17, $326-331$. 
Ueguchi-Tanaka, M., Nakajima, M., Motoyuki, A., Matsuoka, M. (2007) Gibberellin receptor and its role in gibberellin signaling in plants. Annual Review of Plant Biology, 58, 183198.

Uga, Y., Sugimoto, K., Ogawa, S., Rane, J., Ishitani, M., Hara, N., Kitomi, Y., Inukai, Y., Ono, K., Kanno, N., Inoue, H., Takehisa, H., Motoyama, R., Nagamura, Y., Wu, J., Matsumoto, T., Takai, T., Okuno, K., Yano, M. (2013) Control of root system architecture by DEEPER ROOTING1 increases rice yield under drought conditions. Nature Genetics, 45, 1097-1102.

Vance, C.P., Uhde-Stone, C. and Allan, D.L. (2003) Phosphorus acquisition and use: critical adaptations by plants for securing a nonrenewable resource. New Phytologist 157, 423447.

Vidal, E.A., Gutiérrez, R.A. (2008) A systems view of nitrogen nutrient and metabolite responses in Arabidopsis. Current Opinion of Plant Biology, 11, 521-529.

Walch-Liu, P., Ivanov, I.I., Filleur, S., Gan, Y., Remans, T., Forde, B.G. (2006) Nitrogen regulation of root branching. Annals of Botany, 97, 875-881.

Wang, H., Zhu, Y., Fujioka, S., Asami, T., Li, J., Li, J. (2009) Regulation of Arabidopsis brassinosteroid signaling by atypical basic helix-loop-helix proteins. The Plant Cell 21: 3781-3791.

Werner, T., Motyka, V., Strnad, M., Schmülling, T. (2001) Regulation of plant growth by cytokinin. Proceedings of the National Academy of Sciences of the United States of America, 98, 10487-10492.

Werner T, Motyka V, Laucou V, Smets R, Onckelen H.V (2003) Cytokinin-deficient transgenic Arabidopsis plants show functions of cytokinins in the regulation of shoot and root meristem activity. The Plant Cell, 15, 2532-2550.

Wiren, N.V., Gazzarrini, S., Frommer, W.B. (1997) Regulation of mineral nitrogen uptake in plants. Plant and Soil, 196, 191-199. 
Wolters, H., Jürgens, G. (2009) Survival of the flexible: hormonal growth control and adaptation in plant development. Nature Reviews, 10, 305-317.

Woodward, A.W., Bartel, B. (2005) Auxin: regulation, action, and interaction. Annals of Botany, 95, 707-735.

Yu, H.Y., Kang, Y., Liu, Y., Mi, B. (2014) Grafting polyzwitterions onto polyamide by click chemistry and nucleophilic substitution on nitrogen: A novel approach to enhance membrane fouling resistance. Journal of Membrane Science, 449, 50-57.

Zeevaart, J.A.D., Creelman, R.A. (1988) Metabolism and physiology of abscisic acid. Annual Reviews of Plant Physiology and Plant Molecular Biology, 39, 439-473.

Zhang, H., Jennings, A., Barlow, P.W., Forde, B.G. (1999) Dual pathways for regulation of root branching by nitrate. Proceedings of the National Academy of Sciences of the United States of America, 96, 6529-6534.

Zhang, H., Forde, B.G. (2000) Regulation of Arabidopsis root development by nitrate availability. Journal of Experimental Botany, 51, 51-59.

Zheng, Z., Germain, A.D.S., Chory, J. (2014) Unfolding the Mysteries of Strigolactone Signaling. Molecular Plant, 7, 934-936. 